\title{
An Introduction to Sphingolipid Metabolism and Analysis by New Technologies
}

\author{
Yanfeng Chen • Ying Liu • M. Cameron Sullards • \\ Alfred H. Merrill Jr.
}

Received: 5 January 2010/Accepted: 20 July 2010/Published online: 3 August 2010

(C) The Author(s) 2010. This article is published with open access at Springerlink.com

\begin{abstract}
Sphingolipids (SP) are a complex class of molecules found in essentially all eukaryotes and some prokaryotes and viruses where they influence membrane structure, intracellular signaling, and interactions with the extracellular environment. Because of the combinatorial nature of their biosynthesis, there are thousands of SP subspecies varying in the lipid backbones and complex phospho- and glycoheadgroups. Therefore, comprehensive or "sphingolipidomic" analyses (structure-specific, quantitative analyses of all SP, or at least all members of a critical subset) are needed to know which and how much of these subspecies are present in a system as a step toward understanding their functions. Mass spectrometry and related novel techniques are able to quantify a small fraction, but nonetheless a substantial number, of SP and are beginning to provide information about their localization. This review summarizes the basic metabolism of SP and state-of-art mass spectrometric techniques that are producing insights
\end{abstract}

Y. Chen - M. C. Sullards - A. H. Merrill Jr.

School of Chemistry and Biochemistry, The Wallace H. Coulter Department of Biomedical Engineering and the Petit Institute of Bioengineering and Bioscience, Georgia Institute of Technology, Atlanta, GA 30332, USA

Y. Liu · M. C. Sullards · A. H. Merrill Jr. ( $\square)$

School of Biology, The Wallace H. Coulter Department

of Biomedical Engineering, and the Petit Institute of

Bioengineering and Bioscience, Georgia Institute

of Technology, Atlanta, GA 30332, USA

e-mail: al.merrill@biology.gatech.edu

Present Address:

Y. Liu

Department of Human Genetics, Emory University School

of Medicine, Room 325.2 Whitehead Bldg.,

615 Michael Street, Atlanta, GA 30322, USA into SP structure, metabolism, functions, and some of the dysfunctions of relevance to neuromedicine.

Keywords Sphingolipid - Metabolism .

Neurodegenerative diseases - Lipid analysis - Mass spectrometry · Chromatography

\section{Introduction}

Sphingolipids (SP) ${ }^{1}$ are, even today, often thought of as "brain lipids" because many bear names such as sphingomyelins, cerebrosides, gangliosides, etc. They are a complex class of molecules that are found in essentially all animals, plants and fungi, and some prokaryotic organisms and viruses (Merrill et al. 2007). They are defined as a category by the presence of a sphingoid base backbone (mainly sphingosines, So; sphinganines, Sa; and phytosphingosines in mammals, but a wide range of additional species are known) (Pruett et al. 2008) to which can be attached amide-linked fatty acids and (or) a headgroup at the primary hydroxyl. The headgroups range in complexity from a simple $\mathrm{H}$ in ceramide (Cer) to highly complex glycoconjugates (Merrill et al. 2007; Lopez and Schnaar 2009).

SP serve as structural components of membranes, lipoproteins, skin and other biomaterials, and as cell-signaling modulators and mediators. They are located in multiple intracellular organelles, including the plasma membrane, intracellular vesicles and associated organelles (Golgi membranes, endosomes, etc.), mitochondria and even the nucleus (Ledeen and Wu 2008). In some cases, they are

\footnotetext{
1 The abbreviation SP was chosen because it is the category code that has been adopted by the LIPID MAPS Consortium, www.lipidmaps. org.
} 
organized in small, dynamic aggregates within membranes referred to as "rafts" where they can influence the localization and functions of transporters and receptors, such as the AMPA receptor in neurons (Hou et al. 2008). The properties of SP have been reviewed recently for sphingoid bases and Cers (Goni and Alonso 2006; Zheng et al. 2006; Goni and Alonso 2009), and for Cers and more complex species (Maggio et al. 2006; Hakomori 2008; Merrill 2008; Lopez and Schnaar 2009).

The complex carbohydrate moieties of SP are often signatures for particular cell types, and mediate interactions with complementary ligands, such as extracellular matrix proteins and receptors (Hakomori 2000), including direct carbohydrate-carbohydrate binding with headgroups on neighboring cells. For example, gangliosides interact with glycan-binding proteins involved in regulation of nervous system (Quarles 2007; Lopez and Schnaar 2009). SP can interact with proteins on the same cell surface to control the location of the protein (for example, in membrane rafts with other signaling proteins) and modify the conformation of receptors and their activities (Hakomori et al. 1998; Yoon et al. 2006). The functional unit in which glycosphingolipids (GSP) play important roles in cell surface signaling has been referred to as a "glycosynapse" (Hakomori 2002, 2008).

The lipid backbones of SP and their metabolites (sphingoid bases, sphingoid base 1-phosphates, ceramides, ceramide 1-phosphates, and others) serve as mediators of intracellular and extracellular signaling in essentially every type of cell examined, including neurons (Buccoliero and Futerman 2003). The number of biological functions they regulate is large and continues to grow, including neuronal growth (Schwarz et al. 1995; Schwarz and Futerman 1997), differentiation (Milstien et al. 2007) and death (Coetzee et al. 1996; Jana et al. 2009). Thus, it is not surprising that sphingolipids participate in the traditional paradigm of lipid signaling wherein a complex lipid is cleaved to a bioactive backbone that activates or inhibits downstream target(s), but it is somewhat more novel that at least some of the mediators appear also to be generated by de novo biosynthesis (Zheng et al. 2006; Bartke and Hannun 2009). These changes in lipid composition are also likely to alter the properties of the membranes where these conversions take place, increasing or decreasing the rafts and other structures (Hartel et al. 2005; Goni and Alonso 2006), membrane curvature (Goni et al. 2005), transbilayer (flipflop) movement of lipids (Contreras et al. 2005) and other related molecules (Siskind et al. 2006).

This review provides an overview of the basic structures of sphingolipids and their metabolism, then discusses some of the state-of-art technologies that exist and are in development for sphingolipid analysis. It is hoped that this information may help readers understand and study the roles of SP in neuroscience and neuromedicine.

\section{Sphingolipid Structures}

Sphingoid bases vary in alkyl chain length, the position and number of double bonds and hydroxyl groups, and other features (Pruett et al. 2008) Sphingosine (So) is the prevalent backbone of most mammalian SP and refers specifically to $(2 S, 3 R, 4 E)$-2-aminooctadec-4-ene-1, 3-diol and is also referred to as "trans-4-sphingenine". A convenient nomenclature for sphingoid bases is to give the number of hydroxyl groups ( $\mathrm{d}$ for the two, di-, hydroxyls of So and Sa and t, for tri-, for 4-hydroxysphinganine, which is often called phytosphingosine) followed by the chain length (typically 18 carbons) and number of double bonds (most often 0,1 or sometimes 2); therefore, So is abbreviated "d18:1," Sa as "d18:0", and phytosphingosine as "t18:0". The most common structural variations from these sphingoid bases for mammals are the longer chain eicosasphingosines (C20-So or $\mathrm{d} 20: 1$ ) found in brain gangliosides (Colsch et al. 2004), and the presence of a second double bond (d18:2) in some of the sphingolipids found in plasma and brain (Karlsson 1970; Levery 2005; Pruett et al. 2008) (Fig. 1a).

The amide-linked fatty acids found in ceramides also vary in chain length (typically 14-36 carbon atoms), degree of unsaturation (most are saturated, but in some special cases, the fatty acids are highly unsaturated (Sandhoff et al. 2005), and presence or absence of a hydroxyl group on $\alpha$ or $\omega$ carbon atom (Fig. 1a). A simple nomenclature to provide information about both the sphingoid base and the fatty acid of these more complex species has the sphingoid base abbreviation followed by the fatty acid; for example, N-palmitoylsphingosine is abbreviated "d18:1/16:0".

The phosphosphingolipids subcategory includes the sphingoid base 1-phosphates, Cer 1-phosphates (Cer1P), and sphingomyelins (SM), the most prevalent phosphosphingolipid in most mammalian cells, but additional species such as sphingosylphosphocholine (also referred to as lysoSM) and ceramide phosphoethanolamine (Liliom et al. 2001) are also noted.

The major carbohydrates of mammalian GSP are listed in Fig. 1c. The GSP nomenclature (Chester 1998; Fahy et al. 2005) is more complicated by having both common names (such as "ganglioside GM1a" shown in Fig. 1c) and systematic structural nomenclatures (the same compound can be named Neu5Ac $\alpha 2-3(\mathrm{Gal} \beta 1-3 \mathrm{GalNAc} \beta 1-4) \mathrm{Gal} \beta 1$ 4Glc $\beta 1 \mathrm{Cer}$ (d18:1/16:0)) or $\mathrm{II}^{3}-\alpha-\mathrm{N}$-acetylneuraminosylgangliotetraosylCer (abbreviated $\mathrm{II}^{3}-\alpha-\mathrm{Neu} 5 \mathrm{NacGg}_{4} \mathrm{Cer}$ ) by a fairly commonly used system where subcategory (ganglio-, globo-, etc.) connote the root structure for the category, Roman numerals show location of specified carbohydrates, such as sialic acid or other carbohydrate branchpoints) and Arabic superscripts designate the 
Fig. 1 Basic structures of sphingolipids (SP). a the Cer backbone, with $\mathrm{N}$-palmitoylsphingosine as an example; b headgroups of mammalian SP, and c major carbohydrates of glycosphingolipids, and typical symbols, with ganglioside GM1 as an example. The abbreviations are as follows: Glc, glucose; GlcNAc,

$\mathrm{N}$-acetylglucosamine; Gal, galactose; GalNAc,

$\mathrm{N}$-acetylgalactosamine; $\mathrm{Cer}$, ceramide; $\mathrm{LacCer}$, lactose ceramide; GlcCer, glucose ceramide; and NeuAc, $\mathrm{N}$-acetylneuraminic acid
A Lipid backbone

(D-erythro-sphingosine, d18:1, X =11)

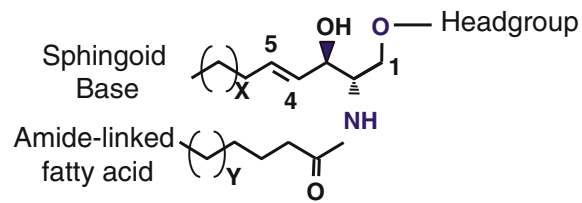

(N-palmitoyl-sphingosine, d18:1/16:0, Y=11)

\section{B Headgroups}

-H (Ceramide)

-Phosphate (Sphingosine 1-Phosphate,

S1P; Ceramide 1-Phosphate, Cer1P)

-Fatty acid (1-O-Acyl-Ceramide)

-Phosphocholine (Sphingomyelin)

-Phosphoethanolamine (Cer PE)

-Glucose (and higher glycan derivatives)

-Galactose (and higher glycan derivatives)

\section{Glycosphingolipid headgroup examples}

GM2 III

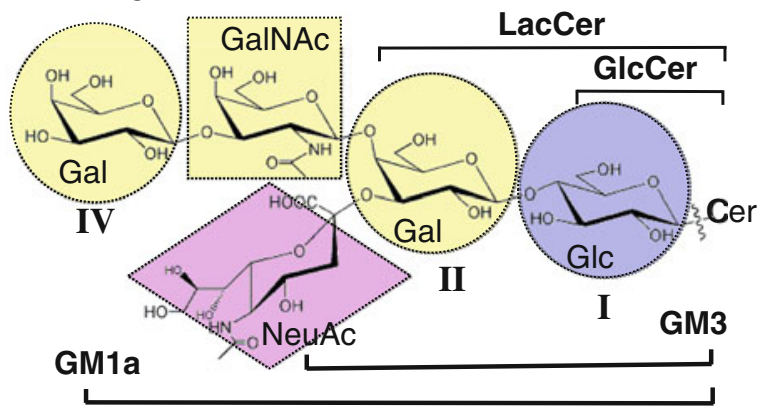

hydroxyl linkage. For more information, see the cited references.

\section{Sphingolipid Metabolism}

Sphingolipid Biosynthesis

The de novo biosynthesis of most SP begins with condensation of L-serine and palmitoyl-CoA by serine palmitoyltransferase (SPT) to form 3-ketosphinganines (Merrill 2002; Hanada 2003) (Fig. 2a). For mammals and yeast, at least two gene products (termed SPTLC1 and SPTLC2, or sometimes SPT1 and SPT2) are necessary for activity (Dickson et al. 2000) and appear to be physically associated (Gable et al. 2000; Hanada et al. 2000). Another SPTLC2-like gene (SPTLC3) has been also discovered, the gene product has been expressed and involved in SPT activity (Hornemann et al. 2006).

As the first unique enzyme of this pathway, SPT is undoubtedly very important in specifying the amounts and types of sphingoid bases made. Mutations in SPTLC1 are associated with hereditary sensory and autonomic neuropathy type I (Bejaoui et al. 2001; Dawkins et al. 2001). And whereas SPT has been thought to only utilize L-serine as its amino acid substrate, recent studies have revealed that L-alanine is used to form a novel sphingoid base, 1-deoxysphinganine (1-deoxySa) (Zitomer et al. 2009). Furthermore, D-serine is a competitive inhibitor with an $\mathrm{IC}_{50}$ that is similar to the $K_{\mathrm{m}}$ for L-serine (Hanada et al. 2000), and this has implications for the mammalian brain that has substantial amounts of D-serine predominantly localized to the forebrain structure (Hashimoto and Oka 1997). SPT is also highly selective for the co-substrate fatty acyl-CoA with the mammalian enzyme, utilizing palmitoyl-CoA (C16:0) > pentadecanoyl- and heptadecanoyl-CoAs (C15:0 and $\mathrm{C} 17: 0)>>$ stearoyl-CoA (C18:0), and essentially no unsaturated species except palmitelaidic (16:1 with a transdouble bond) (Williams et al. 1984; Hanada et al. 2000). This differs from the case when SPT is comprised of SPTLC3, which has a preference for myristoyl-CoA and makes the d16:0 family sphingoid bases (Hornemann et al. 2009).

In the next steps, the 3-ketosphinganine is reduced to Sa by 3-ketosphinganine reductase (Mandon et al. 1992) followed by $\mathrm{N}$-acylated to dihydroceramides (DHCer) by a family of Cer synthases (CerS) (Pewzner-Jung and Futerman 2006). There are at least six mammalian CerS that have varying degrees of specificity for fatty acyl-CoAs (Riebeling et al. 2003; Lahiri and Futerman 2005; Mizutani et al. 2005; Laviad et al. 2008) (Fig. 2a). The resultant DHCer are converted to Cer via insertion of a 4,5-transdouble bond into the sphingoid base backbone by dihydroceramide desaturases (DES1 and DES2) (Michel et al. 1997). In mammalian cells, DES1 appears to have only desaturase activity (Michel et al. 1997), whereas DES2 can perform both desaturation and the 4 hydroxylation that produces phytoceramides (Omae et al. 2004). 
Fig. 2 Sphingolipid

biosynthesis a A biosynthetic pathway for the major subspecies of dihydroceramides (DHCer) and ceramides (Cer) of mammalian SP. Shown from the top is the de novo biosynthesis of sphinganine (d18:0) by serine palmitoyltransferase (SPT) and 3-ketosphinganine reductase (gene name FVT1), followed by either acylation of sphinganine by Cer synthases (shown with their fatty acyl-CoA preferences) or phosphorylation by sphingosine kinase (SphK). b Headgroups added to the subcategories of Cer shown in panel A to make complex SP. Shown on the left bottom panel are Cer at the branch point for formation of sphingomyelins (SM), ceramide phosphoethanolamines (CerPE), Cer 1-phosphates (Cer1P), glucosylceramides (GlcCer), galactosylceramides (GalCer), and 1-O-acylceramide. Also shown on the right panel are the pathways for the sulfatides and root family glycans and combinatorial nature of glycosphingolipid biosynthesis using symbols for the headgroups (shown on the left top panel)

\section{A Biosynthesis of backbone (dihydro -/phyto-)ceramides}

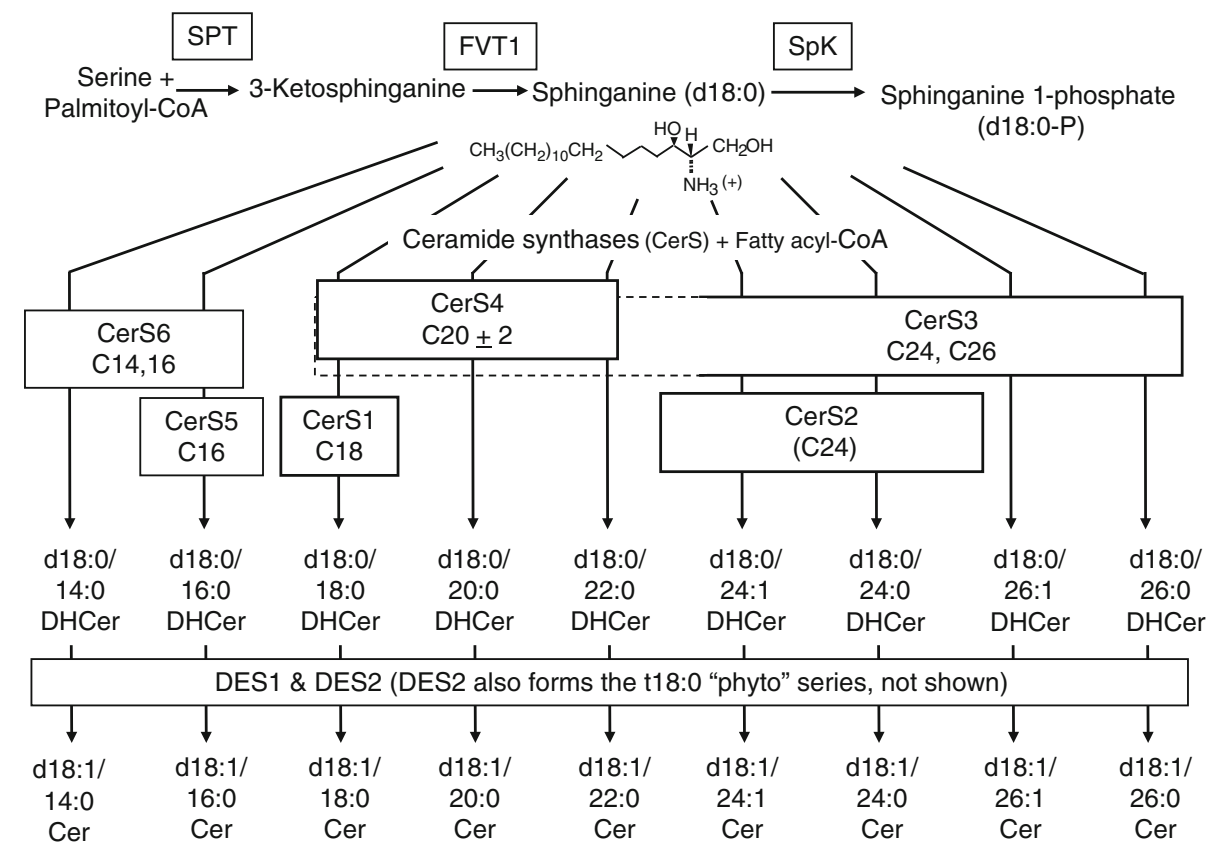

B Headgroups added to (dihydro -/phyto-)ceramides

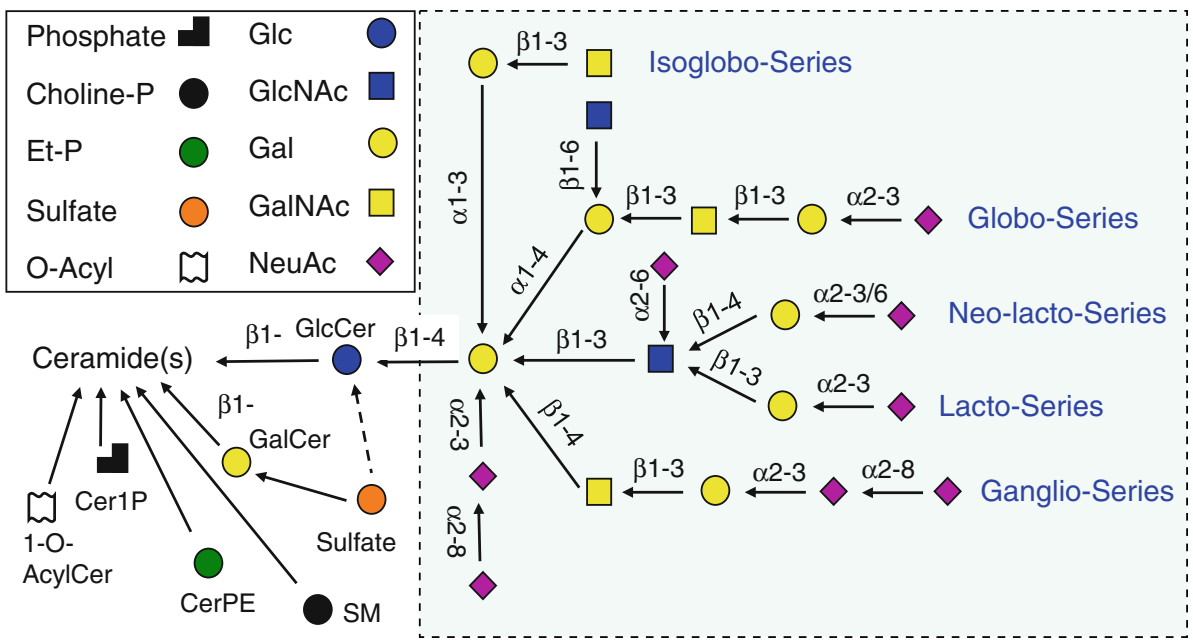

Note that So is not directly made in this pathway; rather, Cer must be hydrolyzed to the free sphingoid base and fatty acids by ceramidase (ceramidases are present in lysosomes and other membranes) (Ferlinz et al. 2001; Linke et al. 2001; Tani et al. 2005). So can then undergo phosphorylation to form sphingosine-1-phosphate (S1P), which is important in cell signaling (Maceyka et al. 2005, 2009) and as an intermediate of SP turnover (sphinganine-1-phosphate, Sa1P, is also made, but its role in signaling is not well defined).

Cer is at the branchpoint for biosynthesis of complex SP (Fig. 2b) by addition of various headgroups: phosphate (from ATP) by ceramide kinase (CerK) (Van Overloop et al. 2006); phosphocholine (for SM) transferred from phosphatidylcholine SM synthases (SMS), with SMS1 localized to the Golgi and SMS2 localized to the plasma membrane (Huitema et al. 2004); phosphoethanolamine for ceramide phosphoethanolamine (CPE) by an SMS1-related enzyme (SMSr) in the ER lumen that has been reported to produce only trace amounts of CPE as a regulator of Cer homeostasis (Vacaru et al. 2009).

GalCer and GlcCer, which are synthesized using uridine diphosphate (UDP)-Glc:Cer glucosyltransferase (CGlcT) and UDP-Gal:Cer galactosyltransferase (CGalT), respectively, by adding the corresponding hexose from UDP-Gal or UDP-Glc (Fig. 2b). The addition of a fatty acid to the 1-hydroxyl has also been described (Shayman and Abe 2000). 
The subcellular localization of GSP biosynthesis is interesting. GalCer is synthesized in the lumen of the ER versus GlcCer, which is thought to be made on cytosolic facing membranes (Sprong et al. 2003). CGalT contains an ER retrieval signal (a KKVK amino acid sequence) at the C-terminus and the active site facing the lumen of the ER at the N-terminus (Sprong et al. 1998) and has access to UDP-Gal that is transported into the lumen of the ER by UDP-Gal transporter 2 (UGT2), a splice variant of UGT1 (the transporter for UDP-Gal into the Golgi) that contains an ER locating dilysine motif (KVKAS) (Kabuss et al. 2005). CGalT is highly expressed in oligodendrocytes and Schwann cells, with a pattern that matches that of myelination (Bosio et al. 1996, 1998), and the disruption of the mouse gene encoding CGalT leads to unstable myelin and progressive paralysis in mouse models (Fewou et al. 2005). GalCer is a substrate for a sulfatotransferase in the ER lumen that utilizes the activated sulfate donor $3^{\prime}$-phosphoadenosine-5' -phosphosulfate to form sulfatides (3'-sulfo-galactosylceramide, ST) (Honke et al. 1997). ST are the major sulfoglycolipids of brain, kidney, the gastrointestinal tract and endometrium, and mammalian male germ cells (Honke and Taniguchi 2003).

Most of the more complex GSP are synthesized by the stepwise addition of carbohydrate molecules (e.g. galactose, $\mathrm{N}$-acetylgalactosamine, and sialic acid) to GlcCer mainly in the Golgi apparatus by particular glycosyltransferases (GTs) (Yu et al. 2004, 2009; Zeng and Yu 2008). Matured GSP are transferred via vesicular transport to the cell surface where they become components of the cell membrane. The nature of the headgroup additions for the root family GSP are illustrated in Fig. 2b. After the initial glycosylations, the pathway divides into ganglio-, lacto-, neolacto-, globo-, and isogloboseries. The downstream pathways, particularly for the gangliosides, have been described as "combinatorial" (Kolter et al. 2002) in analogy to combinatorial synthesis were common starting materials are utilized to make many downstream products by adding them to the reaction vessel in different combinations.

Gangliosides are an interesting prototype for the link between GSP metabolism and biomedicine. It has long been known that gangliosides show significant differences in expression levels and patterns in developing brains (Davidsson et al. 1989; Svennerholm et al. 1989; Ngamukote et al. 2007). For example, total gangliosides increase in adult mouse brains when compared with embryonic mouse brains and the expression pattern of gangliosides shifts from relatively simple subspecies such as GM3 and GD3 to more complex gangliosides, such as GM1, GD1a, GD1b, and GT1b (Ngamukote et al. 2007). The dynamic changes in gangliosides expression also observed during the differentiation of embryonic and mesenchymal stem cells into neural cells (Kwak et al. 2006). Gangliosides bind to myelin-associated glycoprotein (MAG) and play essential roles in maintaining axon-myelin stability and functions (Quarles 2007). Mice lacking the ganglioside biosynthetic gene Galgt1 fail to express complex gangliosides and exhibited central nervous system and peripheral nervous system axon degeneration and dysmyelination quantitatively and qualitatively similar to that of Mag null mice (Pan et al. 2005) and have disruption in the paranodal junctions and ion channel clusters at the nodes of Ranvier (Susuki et al. 2007).

\section{Sphingolipid Turnover}

With the exception of specialized cases of turnover for cell signaling, SP are generally thought to turn over via a process that involves internalization with endocytic vesicles, sorting in early endosomes, and recycling of some portions of the sphingolipid back to the plasma membrane (often with remodeling of the sphingolipid) (Tettamanti et al. 2003) or transport or the remainder to lysosomes where they are degraded by specific acid hydrolases (Kolter and Sandhoff 2006). In lysosome, GSP are catabolized by the stepwise hydrolysis of the terminal monosaccharides through the concerted action of a series of specific exoglycosidases and sphingolipid activator proteins (which include SAP-A, SAP-B, SAP-C or SAP-D, and GM2-activator protein) (Kolter and Sandhoff 2006; Schulze et al. 2009), as summarized in Fig. 3. These pathways are also connected to numerous inherited diseases arising from mutations in the genes encoding these enzymes and/or activator proteins, as is also summarized in Fig. 3. These so-called sphingolipid storage diseases often result in an accumulation of the corresponding lipid substrate in brain (and other organs) (van Echten-Deckert and Herget 2006).

\section{Sphingolipid Analysis}

SP can be analyzed by a variety of traditional methods, such as thin-layer chromatography (TLC), high-performance liquid chromatography (HPLC), immunochemical methodologies, and mass spectrometry (MS), which is the most commonly used method nowadays because it can identify and quantify large numbers of sphingolipid molecules with a high degree of structural accuracy (Sullards 2000; Haynes et al. 2009; Shaner et al. 2009). Various ionization methods have been applied, including electrospray ionization, ESI; atmospheric pressure chemical ionization, APCI, and matrix-assisted laser-desorption ionization (MALDI), combined with triple quadrupole or tandem quadrupolelinear ion trap mass analyzers for MS/MS and $\mathrm{MS}^{\mathrm{n}}$ 


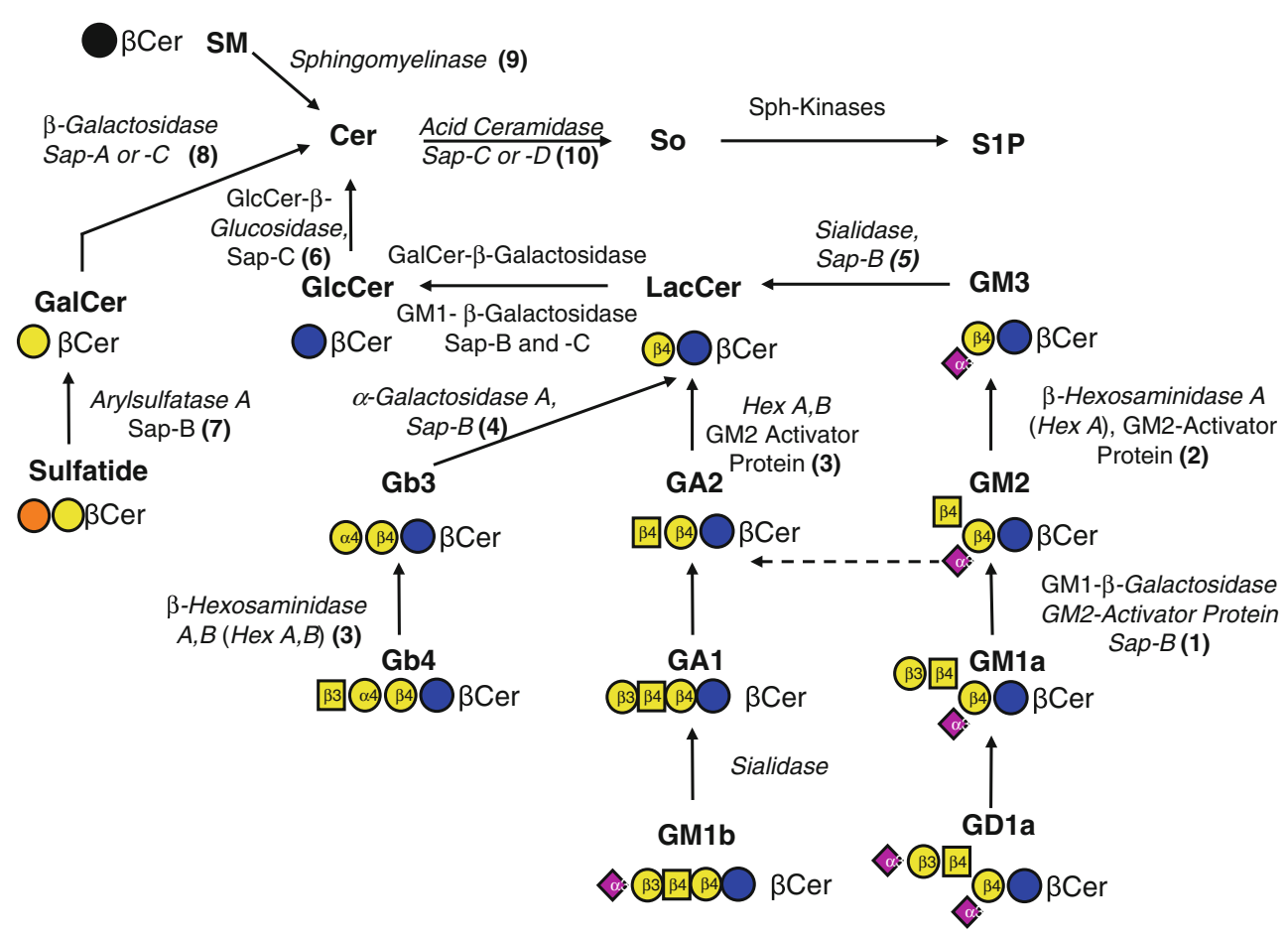

Fig. 3 Catabolism of complex SP and diseases associated with deficiencies in these enzymes and/or activator proteins (Kolter and Sandhoff 2006). The color symbols and scheme for these compounds are the same as shown in Fig. 1 and 2. The SP turnover-related diseases are indicated by number with: (1) GM1-gangliosidosis; (2) Tay-Sachs disease/Sandhoff AB variant; (3) Sandhoff disease; (4)

(Sullards et al. 2007; Shaner et al. 2009), respectively, or for higher mass accuracy, time-of-flight (TOF) (Kirsch et al. 2008), or Fourier transform (FT) instruments (McFarland et al. 2005; Vukelic et al. 2007; Pol et al. 2009).

SP are particularly amenable to ESI and MALDI mass spectrometric analyses because they are relatively easily ionized (thus can be detected with high sensitivity that allows analysis of relatively small numbers of cells) and form fragment ions that are characteristic for the headgroup and backbone subclasses. For examples, both long-chain bases and complex SP ionize well via ESI in the positive ion mode to produce protonated molecular ions $(\mathrm{M}+\mathrm{H})^{+}$. Alternatively, sphingoid base-1-phosphates, ST, SM, and gangliosides form strong ions of the type $(\mathrm{M}-\mathrm{H})^{-}$, $(\mathrm{M}-15)^{-}$, or $(\mathrm{M}-\mathrm{nH})^{\mathrm{n}-}$ (i.e., the original molecular ion minus a proton, a methyl group or multiple hydrogens, respectively) via negative ion ESI, depending on the composition of the solvent (Merrill et al. 2005). The fragmentation profiles for both sphingoid bases and many complex SP can be obtained by MS/MS and multistage tandem MS $\left(\mathrm{MS}^{\mathrm{n}}\right)$ analysis, which provide structural information about the headgroups and types of sphingoid bases and fatty acids in the lipid backbones (Fig. 4).

MALDI usually uses matrix molecules to assist the efficient production of singly charged ions, which in
Fabry disease; (5) Sialidosis; (6) Gaucher disease; (7) metachromatic leukodystrophy; (8) globoid cell leukodystrophy/Krabbe disease; (9) Niemann Pick disease; (10) Farber disease. The abbreviations are as follows: Choline-P phosphatidylcholines; Et-P phosphatidylethanolamine; Glc glucose; GlcNAc N-acetylglucosamine; Gal galactose; GalNAc N-acetylgalactosamine; and NeuAc, $\mathrm{N}$-acetylneuraminic acid

conjunction with the high $m / z$ range of TOF instruments, has aided in the observation of higher molecular weight GSPs. Therefore, studies of more complex GSPs often utilize this technique (Suzuki et al. 2006; Landoni et al. 2008; Chan et al. 2009). One disadvantage of MALDI is that matrices produce abundant background chemical noise at lower $\mathrm{m} / \mathrm{z}$ values, which precludes analysis of free sphingoid bases. However, new advances in matrix choices and high pressure sources may provide an opportunity to study these lower molecular weight SP by MALDI (Nakamura et al. 2006; Cha and Yeung 2007; Stuebiger and Belgacem 2007; Astigarraga et al. 2008; Goto-Inoue et al. 2008; Zarei et al. 2008).

The combination of MS with liquid chromatography (Sommer et al. 2006; Sullards et al. 2007; Shaner et al. 2009) has been successful in meeting difficult analytical challenges by reducing ionization suppression effects from other species and allowing the separation of isomeric and isobaric species, which cannot be achieved by mass spectrometry alone. Two types of HPLC are mainly chosen for SP separation in HPLC-MS/MS: reversed phase LC (Lee et al. 2003; Kaga et al. 2005; Merrill et al. 2005; Shaner et al. 2009) for separations based on the length and saturation of acyl chains (for example, to separate So and Sa) and normal phase LC (Pettus et al. 2004; Merrill et al. 2005; Pacetti et al. 2005; Farwanah et al. 2007; Farwanah 
Fig. 4 Major fragmentation sites of SP and ions that are often used for analysis by electrospray ionization tandem mass spectrometry in the positive ion mode (Merrill et al. 2005)

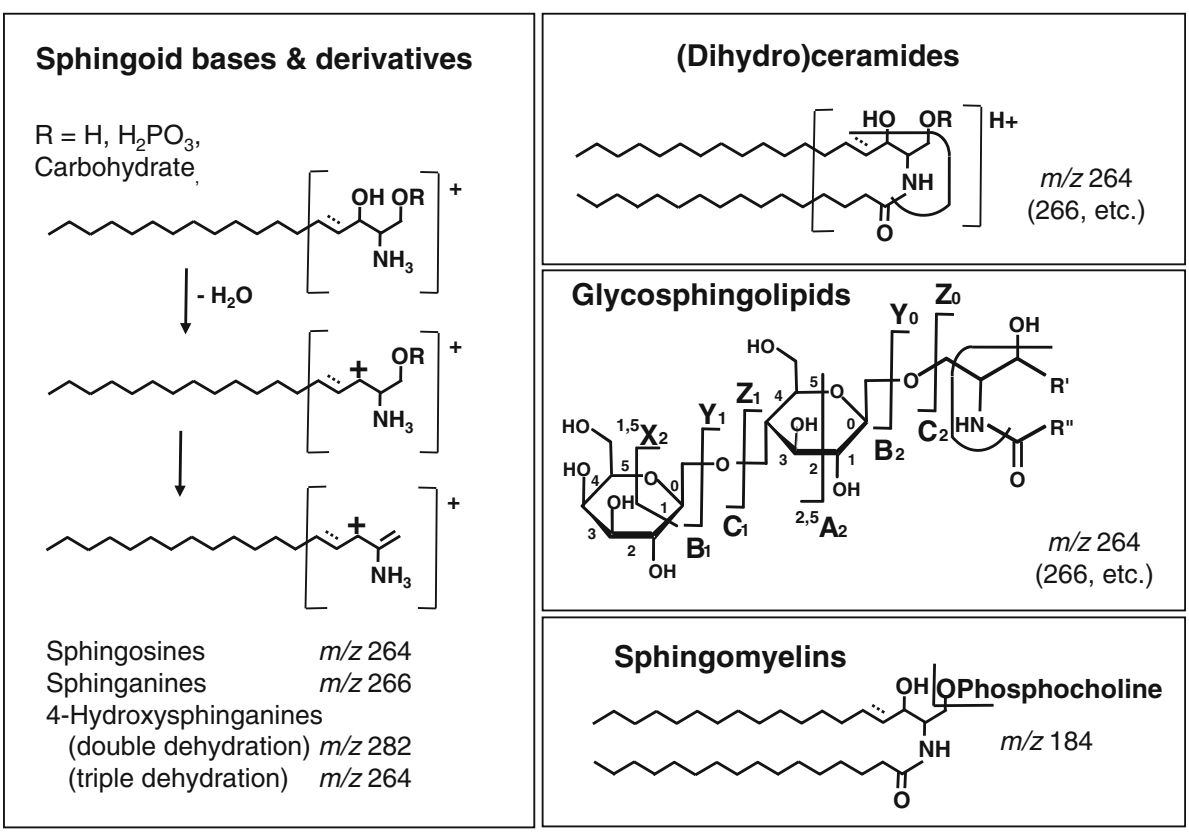

et al. 2009) to separate compounds primarily by their headgroup constituents (for example, distinguish Cer, GlcCer, LacCer, globotriaosylceramide, globotetraosylceramide, SM as well as cholesterol, etc.). HPLC-MS/MS has been used to quantify and determine the structures of free sphingoid bases, free sphingoid base phosphate, Cer, monohexosylceramide (both GalCer and GluCer), LacCer, SM (Sullards and Merrill 2001; Pettus et al. 2003; Bielawski et al. 2006; Yoo et al. 2006), and more complex GSP (Merrill et al. 2005; Ikeda et al. 2008).

Currently, LC-ESI MS/MS is the most popular analytical tool for sphingolipid analysis, because it provides (1) a high level of specificity with regard to differentiation of complex molecular species via retention time, precursor ion $\mathrm{m} / \mathrm{z}$ value, and structure-specific product ion $\mathrm{m} / \mathrm{z}$, value, (2) high sensitivities that are orders of magnitude better than those of classical techniques, which enables detection of SP in minute quantities ( $\sim$ fmol or less) in small biological samples ( $\sim 10^{6}$ cells), (3) a wide dynamic range (typically several orders of magnitude) for quantitation of $\mathrm{SP}$, and (4) the potential of accurate and precise quantitation in complicated biological samples using appropriate internal standards (C. Haynes, 2009). Different classes of gangliosides (i.e. GM1, GM2, GM3, GD3, GD1a, GD1b, GT1b, GQ1b) in the rat brain can be fast and efficiently quantified with high sensitivity using LC-ESI MS/MS (Fong et al. 2009). Regioisomeric gangliosides, such as GM1a and GM1b, GD1a, GD1b, and GD1c, and GT1a, GT1b, and GT1c, with diagnostic sugar chains have also been effectively separated and distinguished by theoretically expanded multiple reaction monitoring of LC-ESI MS/MS (Ikeda et al. 2008).

\section{New Technologies for Sphingolipid Analysis}

Although the methods described earlier are powerful approaches to study many SP, there still are many challenges for sphingolipidomic analysis, which refer to the structure-specific and quantitative measurements of all the individual molecular species of SP so that the quantity of each one in a given biological context (i.e. manipulated biosynthesis or turnover) may be determined. The sphingolipidome could contain tens of thousands of SP because there are over 400 headgroup subcategories in mammals alone (www.sphingomap.org) (Merrill et al. 2007, 2009), and many have at least several to a few dozen backbone variants on sphingoid bases and fatty acids. The current analytical challenges include the needs for profiling all the $\mathrm{SP}$ in a specific biological system (such as central nervous system), knowing the location of these molecules, and obtaining information about their metabolic flux.

Two-dimensional (2-D) ESI MS/MS techniques have been introduced for the identification, structure determination, and quantitation of sphingolipidomic analysis (Han and Gross 2003; Han and Jiang 2009; Stahlman et al. 2009). This technique (also called "shotgun" lipidomics) utilizes MS and MS/MS in both positive and negative ESI conditions to analyze an infusion sample (usually dissolved in chloroform, which provides good lipid solubility and high sensitivity). The formation of charged molecular adducts in the positive mode and anionic species in the negative mode is promoted by the presence of aqueous $\mathrm{LiOH}$ and $\mathrm{LiCl}$, respectively. This technique is a relatively fast and simple method to profile many SP and glycerol lipids in crude lipid extracts. It has been used to examine the lipid composition 
of the brain mitochondria, which can help to determine whether intrinsic lipid abnormalities underlie mitochondrial dysfunction associated with neurological and neurodegenerative diseases (Kiebish et al. 2009). A variety of very-lowabundance sphingolipid classes (e.g., So, psychosine, and lysosphingomyelin) and other SP species (e.g., SM) in brain were also identified and quantitated using this approach (Jiang et al. 2007). However, it should be noted that the possibility of ionization suppression and the inability to distinguish isomeric and isobaric species are main limitations of this non-LC method.

The use of nanospray combined with high resolution MS and MS/MS analysis via tandem mass spectrometers is an innovative extension of the 2-D lipid profiling technique (Ekroos et al. 2002). This method usually uses a chip containing a high-density array of nanospray nozzles to infuse very small volumes of sample into the mass spectrometer. It allows numerous product ion analyses to be performed incrementally across a desired mass range. The resulting product ion data is then queried for structurespecific fragment ions or neutral losses corresponding to unique lipid fragmentations to reveal the individual headgroup, fatty acid, and sphingoid base combinations of various intact lipid species in the sample. The high resolution and mass accuracy of the mass analyzer also allows a narrower precursor ion window, resulting in a better selection of lipid of interest (Haynes et al. 2009). Chipbased nanoelectrospray ionization tandem mass spectrometry has demonstrated the capability of observing structural and composition differences of gangliosides (such as trisialoganglioside subspecies with different fatty acid chain lengths) between normal and benign tumorous frontal cortex tissues (Schiopu et al. 2009). It has also been used to identify complex and distinctive gangliosides (such as GD, GT, GM, LM, GQ subspecies) in human gliosarcoma (Vukelic et al. 2007). Since all infusion-based techniques have limitations concerning unambiguous identification and, more importantly, quantitation of SP, newer chipbased nanospray systems allow the HPLC column to be directly coupled to the chip and enable simultaneous fraction collection of excess eluent. Using this technology, complex mixtures can be separated, and the analytes are selectively eluted under conditions with minimized ionization suppression effects. Isotopic, isomeric, and isobaric effects can also be differentiated easily. The resulting LC-MS or MS/MS data may then be used for quantitation when the kinetic and dynamic range problems are solved and the appropriate internal standards are included. Detailed structural information can also be obtained by analyzing a particular fraction containing an analyte of interest in greater detail (i.e. $\mathrm{MS}^{\mathrm{n}}$ ) (Haynes et al. 2009).

The recent development of ion mobility mass spectrometry has demonstrated additional possibilities to achieve separation of lipids (Jackson et al. 2005). In this technique, different ions with the same $\mathrm{m} / \mathrm{z}$ value (isomers) are separated based on differences in their mobility through a buffer gas and applied electric field (Verbeck et al. 2002). The mobilities of different ions are directly affected by their three-dimensional shapes, e.g. ions with a greater crosssection migrate slower (Verbeck et al. 2002; Fenn et al. 2009; Trimpin et al. 2009). Thus, it is possible to distinguish the different conformations of ions having the same $\mathrm{m} / \mathrm{z}$ (Liu and Clemmer 1997; Clowers et al. 2005). This new technology offers the potential to differentiate isomeric sphingolipid species for subsequent identification and quantitation that currently can only be achieved via LC.

Imaging mass spectrometry is another emerging technology that not only identifies various classes of molecules but also determines their spatial distributions in biological samples. Imaging mass spectrometry is beginning to allow analysis of SP in situ using samples such as thin slices of tissue, cultured cells and model membranes. One of the methods is MALDI imaging mass spectrometry in which samples (such as brain slices) are placed on a MALDI plate, imbedded as uniformly and non-disruptively as possible with matrix material serving to enhance the desorption and ionization of analytes in the sample. Then, the sample is scanned by the laser beam incrementally to generate discrete mass spectra (Chaurand et al. 2006; Roy et al. 2006; Jackson et al. 2007a; b) The intensity of a specific ion of interest can then be assigned different colors and plotted in $x, y$-space to yield a molecular image of the biological sample. This may then be cross-referenced with a histologic image using standard methods generated from the same sample or a similar neighboring sample. In another imaging technique, secondary ion mass spectrometry (SIMS), a beam of primary ions is tightly focused to impinge on the surface of the biological sample to ionize compounds of interest (Sjovall et al. 2004; Roy et al. 2006; Benabdellah et al. 2010). SIMS provides better spatial resolution for lower mass species than MALDI, whereas MALDI is more amenable to higher mass analytes. An additional ambient imaging technique, desorption electrospray ionization (DESI), uses charged droplets of solvent generated from an electrospray to generate the secondary ions to provide molecular image of biological samples with much easier experimental procedure but even lower spatial resolution than MALDI imaging (Wiseman et al. 2006; Manicke et al. 2008). Additional techniques are emerging where MALDI is combined with another method of ion separation, such as ion mobility-MS which gives twodimensional separations based on analyte apparent surface area or collision cross section as well as mass-to-charge [McLean et al. (2007)].

Applied to brain tissues, MALDI imaging has observed primary SP such as SM, monohexosylceramides, ST, and 
gangliosides (Jackson et al. 2007b; Jackson and Woods 2009; Murphy et al. 2009) as well as the specific localization of their subcategories in different brain regions. It has been reported that the cerebellar cortex contains small amounts of SM and larger amounts of gangliosides GM1, GD1, and GT1, whereas the cerebellar peduncle contains sulfatides and primarily GM1 with smaller quantities of GD1 (Woods and Jackson 2006). In another study of TaySachs and Sandhoff disease, MALDI imaging mass spectrometry, GM2 and asialo-GM2 (GA2) subspecies were found highly elevated in diseased brain and specifically localized in the granular cell region of the cerebellum, whereas ST was localized mainly in myelinated fiber (white matter) region of the cerebellum as well as in the brain stem with a relatively uniform distribution and had similar relative signal intensity for both normal and diseased brain. Many subcategories of other lipids (such as phosphatidylcholines, phosphatidylinositol, plasmenylethanolamine, phosphatidylserine) were also localized to specific regions of the brain (Chen et al. 2008a). Longchain base (LCB) gangliosides with $\mathrm{C} 18$ - or C20-sphingosine have also been found to localize differentially in the mouse brain by MALDI imaging mass spectrometry (Chen et al. 2008b; Sugiura et al. 2008). The C18-species was widely localized throughout the frontal brain, whereas the $\mathrm{C} 20$-species selectively distributed along the entorhinal-hippocampus projections, especially in the molecular layer of the dentate gyrus (Sugiura et al. 2008). SIMS TOF has also been used to analyze brain slices to reveal the different distributions of GalCer subspecies in white matter. The $\mathrm{C} 18$ GalCer subspecies were mainly found in cholesterol-rich areas, whereas C24 GalCer subspecies were primarily distributed in $\mathrm{Na}^{+}-$and $\mathrm{K}^{+}$enriched regions (Borner et al. 2006). While imaging mass spectrometry has limitations with respect to providing quantitative information (Murphy et al. 2009), the ability to reveal the cellular-and eventually subcellular-location of the molecules of interest will be a major complement to sphingolipid analysis and sphingolipidomic biology.

\section{Conclusion}

SP are comprised of thousands of species that encompass bioactive backbones and complex phospho- and glycolipids that nature has chosen to make for equally sophisticated biological functions. The challenge for researchers is to develop methods that are powerful enough to deal with this complexity. Although there is still a long way to go, the application of relatively recently developed analytical methods for SP is already helping clarify the roles of these compounds in neural cell behavior and disease.
Acknowledgments The authors thank colleagues at Georgia Tech (Dr. Chris Haynes, Elaine Wang, Samuel Kelly, and others) and the NIH funding of the LIPID MAPS Consortium (NIH grant U54 GM069338) for the support that has made the research by the coauthors of this review possible.

Open Access This article is distributed under the terms of the Creative Commons Attribution Noncommercial License which permits any noncommercial use, distribution, and reproduction in any medium, provided the original author(s) and source are credited.

\section{References}

Astigarraga, E., Barreda-Gomez, G., Lombardero, L., Fresnedo, O., Castano, F., Giralt, M. T., et al. (2008). Profiling and imaging of lipids on brain and liver tissue by matrix-assisted laser desorption/ionization mass spectrometry using 2-mercaptobenzothiazole as a matrix. Analytical Chemistry, 80, 9105-9114.

Bartke, N., \& Hannun, Y. A. (2009). Bioactive sphingolipids: Metabolism and function. Journal of Lipid Research, 50(Suppl), S91-S96.

Bejaoui, K., Wu, C., Scheffler, M. D., Haan, G., Ashby, P., Wu, L., et al. (2001). SPTLC1 is mutated in hereditary sensory neuropathy, type 1. Nature Genetics, 27, 261-262.

Benabdellah, F., Seyer, A., Quinton, L., Touboul, D., Brunelle, A., \& Laprevote, O. (2010). Mass spectrometry imaging of rat brain sections: Nanomolar sensitivity with MALDI versus nanometer resolution by TOF-SIMS. Analytical and Bioanalytical Chemistry, 396, 151-162.

Bielawski, J., Szulc, Z. M., Hannun, Y. A., \& Bielawska, A. (2006). Simultaneous quantitative analysis of bioactive sphingolipids by high-performance liquid chromatography-tandem mass spectrometry. Methods, 39, 82-91.

Borner, K., Nygren, H., Hagenhoff, B., Malmberg, P., Tallarek, E., \& Mansson, J. E. (2006). Distribution of cholesterol and galactosylceramide in rat cerebellar white matter. Biochimica et Biophysica Acta, 1761, 335-344.

Bosio, A., Binczek, E., Haupt, W. F., \& Stoffel, W. (1998). Composition and biophysical properties of myelin lipid define the neurological defects in galactocerebroside- and sulfatidedeficient mice. Journal of Neurochemistry, 70, 308-315.

Bosio, A., Binczek, E., \& Stoffel, W. (1996). Functional breakdown of the lipid bilayer of the myelin membrane in central and peripheral nervous system by disrupted galactocerebroside synthesis. Proceedings of the National Academy of Sciences of the United States of America, 93, 13280-13285.

Buccoliero, R., \& Futerman, A. H. (2003). The roles of ceramide and complex sphingolipids in neuronal cell function. Pharmacological Research, 47, 409-419.

Cha, S., \& Yeung, E. S. (2007). Colloidal graphite-assisted laser desorption/ionization mass spectrometry and msn of small molecules. 1. Imaging of cerebrosides directly from rat brain tissue. Analytical Chemistry, 79, 2373-2385.

Chan, K., Lanthier, P., Liu, X., Sandhu, J. K., Stanimirovic, D., \& Li, J. (2009). MALDI mass spectrometry imaging of gangliosides in mouse brain using ionic liquid matrix. Analytica Chimica Acta, 639, 57-61.

Chaurand, P., Cornett, D. S., \& Caprioli, R. M. (2006). Molecular imaging of thin mammalian tissue sections by mass spectrometry. Current Opinion in Biotechnology, 17, 431-436.

Chen, Y., Allegood, J., Liu, Y., Wang, E., Cachon-Gonzalez, B., Cox, T. M., et al. (2008). Imaging MALDI mass spectrometry using an oscillating capillary nebulizer matrix coating system and its 
application to analysis of lipids in brain from a mouse model of Tay-Sachs/Sandhoff disease. Analytical Chemistry, 80, 2780-2788.

Chester, M. A. (1998). IUPAC-IUB Joint Commission on Biochemical Nomenclature (JCBN). Nomenclature of glycolipids-recommendations 1997. European Journal of Biochemistry, 257, 293-298.

Clowers, B. H., Dwivedi, P., Steiner, W. E., Hill, H. H., \& Bendiak, B. (2005). Separation of sodiated isobaric disaccharides and trisaccharides using electrospray ionization-atmospheric pressure ion mobility-time of flight mass spectrometry. Journal of the American Society for Mass Spectrometry, 16, 660-669.

Coetzee, T., Fujita, N., Dupree, J., Shi, R., Blight, A., Suzuki, K., et al. (1996). Myelination in the absence of galactocerebroside and sulfatide: normal structure with abnormal function and regional instability. Cell, 86, 209-219.

Colsch, B., Afonso, C., Popa, I., Portoukalian, J., Fournier, F., Tabet, J. C., et al. (2004). Characterization of the ceramide moieties of sphingoglycolipids from mouse brain by ESI-MS/MS: identification of ceramides containing sphingadienine. Journal of Lipid Research, 45, 281-286.

Contreras, F. X., Basanez, G., Alonso, A., Herrmann, A., \& Goni, F. M. (2005). Asymmetric addition of ceramides but not dihydroceramides promotes transbilayer (flip-flop) lipid motion in membranes. Biophysical Journal, 88, 348-359.

Davidsson, P., Fredman, P., Collins, V. P., von Holst, H., Mansson, J. E., \& Svennerholm, L. (1989). Ganglioside composition in human meningiomas. Journal of Neurochemistry, 53, 705-709.

Dawkins, J. L., Hulme, D. J., Brahmbhatt, S. B., Auer-Grumbach, M., \& Nicholson, G. A. (2001). Mutations in SPTLC1, encoding serine palmitoyltransferase, long chain base subunit-1, cause hereditary sensory neuropathy type I. Nature Genetics, 27, 309-312.

Dickson, R. C., Lester, R. L., \& Nagiec, M. M. (2000). Serine palmitoyltransferase. Methods in Enzymology, 311, 3-9.

Ekroos, K., Chernushevich, I. V., Simons, K., \& Shevchenko, A. (2002). Quantitative profiling of phospholipids by multiple precursor ion scanning on a hybrid quadrupole time-of-flight mass spectrometer. Analytical Chemistry, 74, 941-949.

Fahy, E., Subramaniam, S., Brown, H. A., et al. (2005). A comprehensive classification system for lipids. Journal of Lipid Research, 46, 839-861.

Farwanah, H., Pierstorff, B., Schmelzer, C. E. H., Raith, K., Neubert, R. H. H., Kolter, T., et al. (2007). Separation and mass spectrometric characterization of covalently bound skin ceramides using LC/APCI-MS and Nano-ESI-MS/MS. Journal of Chromatography. B, Analytical Technologies in the Biomedical and Life Sciences, 852, 562-570.

Farwanah, H., Wirtz, J., Kolter, T., Raith, K., Neubert, R. H. H., \& Sandhoff, K. (2009). Normal phase liquid chromatography coupled to quadrupole time of flight atmospheric pressure chemical ionization mass spectrometry for separation, detection and mass spectrometric profiling of neutral sphingolipids and cholesterol. Journal of Chromatography. B, Analytical Technologies in the Biomedical and Life Sciences, 877, 2976-2982.

Fenn, L. S., Kliman, M., Mahsut, A., Zhao, S. R., \& McLean, J. A. (2009). Characterizing ion mobility-mass spectrometry conformation space for the analysis of complex biological samples. Analytical and Bioanalytical Chemistry, 394, 235-244.

Ferlinz, K., Kopal, G., Bernardo, K., et al. (2001). Human acid ceramidase: processing, glycosylation, and lysosomal targeting. The Journal of Biological Chemistry, 276, 35352-35360.

Fewou, S. N., Bussow, H., Schaeren-Wiemers, N., Vanier, M. T., Macklin, W. B., Gieselmann, V., et al. (2005). Reversal of nonhydroxy:alpha-hydroxy galactosylceramide ratio and unstable myelin in transgenic mice overexpressing UDP-galactose:ceramide galactosyltransferase. Journal of Neurochemistry, 94, 469-481.
Fong, B., Norris, C., Lowe, E., \& McJarrow, P. (2009). Liquid chromatography-high-resolution mass spectrometry for quantitative analysis of gangliosides. Lipids, 44, 867-874.

Gable, K., Slife, H., Bacikova, D., Monaghan, E., \& Dunn, T. M. (2000). Tsc3p is an 80-amino acid protein associated with serine palmitoyltransferase and required for optimal enzyme activity. The Journal of Biological Chemistry, 275, 7597-7603.

Goni, F. M., \& Alonso, A. (2006). Biophysics of sphingolipids I. Membrane properties of sphingosine, ceramides and other simple sphingolipids. Biochimica et Biophysica Acta, 1758, 1902-1921.

Goni, F. M., \& Alonso, A. (2009). Effects of ceramide and other simple sphingolipids on membrane lateral structure. Biochimica et Biophysica Acta, 1788, 169-177.

Goni, F. M., Contreras, F. X., Montes, L. R., Sot, J., \& Alonso, A. (2005) Biophysics (and sociology) of ceramides. Biochemical Society Symposium, pp 177-188.

Goto-Inoue, N., Hayasaka, T., Sugiura, Y., Taki, T., Li, Y.-T., Matsumoto, M., et al. (2008). High-sensitivity analysis of glycosphingolipids by matrix-assisted laser desorption/ionization quadrupole ion trap time-of-flight imaging mass spectrometry on transfer membranes. Journal of Chromatography. B, Analytical Technologies in the Biomedical and Life Sciences, 870, 74-83.

Hakomori, S. I. (2000). Cell adhesion/recognition and signal transduction through glycosphingolipid microdomain. Glycoconjugate Journal, 17, 143-151.

Hakomori, S. I. (2002). Inaugural Article: The glycosynapse. Proceedings of the National Academy of Sciences of the United States of America, 99, 225-232.

Hakomori, S.-i. (2008). Structure and function of glycosphingolipids and sphingolipids: Recollections and future trends. Biochimica et Biophysica Acta, General Subjects, 1780, 325-346.

Hakomori, S., Yamamura, S., \& Handa, A. K. (1998). Signal transduction through glyco(sphingo)lipids. Introduction and recent studies on glyco(sphingo)lipid-enriched microdomains. Annals of the New York Academy of Sciences, 845, 1-10.

Han, X., \& Gross, R. W. (2003). Global analyses of cellular lipidomes directly from crude extracts of biological samples by ESI mass spectrometry: a bridge to lipidomics. Journal of Lipid Research, 44, 1071-1079.

Han, X., \& Jiang, X. (2009). A review of lipidomic technologies applicable to sphingolipidomics and their relevant applications. European Journal of Lipid Science and Technology, 111, 39-52.

Hanada, K. (2003). Serine palmitoyltransferase, a key enzyme of sphingolipid metabolism. Biochimica et Biophysica Acta, 1632, $16-30$.

Hanada, K., Nishijima, M., Fujita, T., \& Kobayashi, S. (2000). Specificity of inhibitors of serine palmitoyltransferase (SPT), a key enzyme in sphingolipid biosynthesis, in intact cells - A novel evaluation system using an SPT-defective mammalian cell mutant. Biochemical Pharmacology, 59, 1211-1216.

Hartel, S., Fanani, M. L., \& Maggio, B. (2005). Shape transitions and lattice structuring of ceramide-enriched domains generated by sphingomyelinase in lipid monolayers. Biophysical Journal, 88, 287-304.

Hashimoto, A., \& Oka, T. (1997). Free D-aspartate and D-serine in the mammalian brain and periphery. Progress in Neurobiology, $52,325-353$.

Haynes, C. A., Allegood, J. C., Park, H., \& Sullards, M. C. (2009). Sphingolipidomics: Methods for the comprehensive analysis of sphingolipids. Journal of Chromatography. B, Analytical Technologies in the Biomedical and Life Sciences, 877, 2696-2708.

Honke, K., Hasui, M., \& Takano, N. (1997). Abnormal metabolism of fatty acids and ketone bodies in Duchenne muscular dystrophy, and the effect of biotin on these abnormalities. No To Hattatsu, $29,13-18$. 
Honke, K., \& Taniguchi, N. (2003). Functions of Gal 3-sulfotransferases. Tanpakushitsu kakusan koso, 48, 963-966.

Hornemann, T., Penno, A., Rutti, M. F., Ernst, D., Kivrak-Pfiffner, F., Rohrer, L., et al. (2009). The SPTLC3 subunit of serine palmitoyltransferase generates short chain sphingoid bases. The Journal of Biological Chemistry, 284, 26322-26330.

Hornemann, T., Richard, S., Rutti, M. F., Wei, Y., \& von Eckardstein, A. (2006). Cloning and initial characterization of a new subunit for mammalian serine-palmitoyltransferase. The Journal of Biological Chemistry, 281, 37275-37281.

Hou, Q., Huang, Y., Amato, S., Snyder, S. H., Huganir, R. L., \& Man, H. Y. (2008). Regulation of AMPA receptor localization in lipid rafts. Molecular and Cellular Neurosciences, 38, 213-223.

Huitema, K., van den Dikkenberg, J., Brouwers, J. F., \& Holthuis, J. C. (2004). Identification of a family of animal sphingomyelin synthases. EMBO Journal, 23, 33-44.

Ikeda, K., Shimizu, T., \& Taguchi, R. (2008). Targeted analysis of ganglioside and sulfatide molecular species by LC/ESI-MS/MS with theoretically expanded multiple reaction monitoring. Journal of Lipid Research, 49, 2678-2689.

Jackson, S. N., Ugarov, M., Egan, T., Post, J. D., Langlais, D., Albert Schultz, J., et al. (2007a). MALDI-ion mobility-TOFMS imaging of lipids in rat brain tissue. Journal of Mass Spectrometry and Ion Physics, 42, 1093-1098.

Jackson, S. N., Wang, H. Y., \& Woods, A. S. (2007b). In situ structural characterization of glycerophospholipids and sulfatides in brain tissue using MALDI-MS/MS. Journal of the American Society for Mass Spectrometry, 18, 17-26.

Jackson, S. N., Wang, H. Y., Woods, A. S., Ugarov, M., Egan, T., \& Schultz, J. A. (2005). Direct tissue analysis of phospholipids in rat brain using MALDI-TOFMS and MALDI-ion mobilityTOFMS. Journal of the American Society for Mass Spectrometry, 16, 133-138.

Jackson, S. N., \& Woods, A. S. (2009). Direct profiling of tissue lipids by MALDI-TOFMS. Journal of Chromatography. B, Analytical Technologies in the Biomedical and Life Sciences, 877, 2822-2829.

Jana, A., Hogan, E. L., \& Pahan, K. (2009). Ceramide and neurodegeneration: susceptibility of neurons and oligodendrocytes to cell damage and death. Journal of the Neurological Sciences, 278, 5-15.

Jiang, X., Cheng, H., Yang, K., Gross, R. W., \& Han, X. (2007). Alkaline methanolysis of lipid extracts extends shotgun lipidomics analyses to the low-abundance regime of cellular sphingolipids. Analytical Biochemistry, 371, 135-145.

Kabuss, R., Ashikov, A., Oelmann, S., Gerardy-Schahn, R., \& Bakker, H. (2005). Endoplasmic reticulum retention of the large splice variant of the UDP-galactose transporter is caused by a dilysine motif. Glycobiology, 15, 905-911.

Kaga, N., Kazuno, S., Taka, H., Iwabuchi, K., \& Murayama, K. (2005). Isolation and mass spectrometry characterization of molecular species of lactosylceramides using liquid chromatography-electrospray ion trap mass spectrometry. Analytical Biochemistry, 337, 316-324.

Karlsson, K.-A. (1970). On the chemistry and occurrence of sphingolipid long-chain bases. Chemistry and Physics of Lipids, $1,6-43$.

Kiebish, M. A., Han, X., \& Seyfried Thomas, N. (2009). Examination of the brain mitochondrial lipidome using shotgun lipidomics. Methods in Molecular Biology (Clifton, N.J.), 579, 3-18.

Kirsch, S., Zarei, M., Cindric, M., Muthing, J., Bindila, L., \& PeterKatalinic, J. (2008). On-line nano-HPLC/ESI QTOF MS and tandem MS for separation, detection, and structural elucidation of human erythrocytes neutral glycosphingolipid mixture. Analytical Chemistry, 80, 4711-4722.
Kolter, T., Proia, R. L., \& Sandhoff, K. (2002). Combinatorial ganglioside biosynthesis. The Journal of Biological Chemistry, 277, 25859-25862.

Kolter, T., \& Sandhoff, K. (2006). Sphingolipid metabolism diseases. Biochimica et Biophysica Acta, 1758, 2057-2079.

Kwak, D. H., Yu, K., Kim, S. M., et al. (2006). Dynamic changes of gangliosides expression during the differentiation of embryonic and mesenchymal stem cells into neural cells. Experimental Biology and Medicine, 38, 668-676.

Lahiri, S., \& Futerman, A. H. (2005). LASS5 is a bona fide dihydroceramide synthase that selectively utilizes palmitoylCoA as acyl donor. The Journal of Biological Chemistry, 280, 33735-33738.

Landoni, M., Duschak, V. G., Erra-Balsells, R., \& Couto, A. S. (2008). UV-MALDI Mass Spectrometry Analysis of NBDGlycosphingolipids Without an External Matrix. Journal of the American Society for Mass Spectrometry, 19, 923-926.

Laviad, E. L., Albee, L., Pankova-Kholmyansky, I., Epstein, S., Park, H., Merrill, A. H., Jr., et al. (2008). Characterization of ceramide synthase 2: Tissue distribution, substrate specificity, and inhibition by sphingosine 1-phosphate. The Journal of Biological Chemistry, 283, 5677-5684.

Ledeen, R. W., \& Wu, G. (2008). Nuclear sphingolipids: metabolism and signaling. Journal of Lipid Research, 49, 1176-1186.

Lee, M. H., Lee, G. H., \& Yoo, J. S. (2003). Analysis of ceramides in cosmetics by reversed-phase liquid chromatography/electrospray ionization mass spectrometry with collision-induced dissociation. Rapid Communications in Mass Spectrometry, 17, 64-75.

Levery, S. B. (2005). Glycosphingolipid structural analysis and glycosphingolipidomics. Methods in Enzymology, 405, 300-369.

Liliom, K., Sun, G., Bunemann, M., et al. (2001). Sphingosylphosphocholine is a naturally occurring lipid mediator in blood plasma: A possible role in regulating cardiac function via sphingolipid receptors. Biochemical Journal, 355, 189-197.

Linke, T., Wilkening, G., Sadeghlar, F., Mozcall, H., Bernardo, K., Schuchman, E., et al. (2001). Interfacial regulation of acid ceramidase activity. Stimulation of ceramide degradation by lysosomal lipids and sphingolipid activator proteins. The Journal of Biological Chemistry, 276, 5760-5768.

Liu, Y. S., \& Clemmer, D. E. (1997). Characterizing oligosaccharides using injected-ion mobility mass spectrometry. Analytical Chemistry, 69, 2504-2509.

Lopez, P. H., \& Schnaar, R. L. (2009). Gangliosides in cell recognition and membrane protein regulation. Current Opinion in Structural Biology, 19, 549-557.

Maceyka, M., Milstien, S., \& Spiegel, S. (2009). Sphingosine-1phosphate: The Swiss army knife of sphingolipid signaling. Journal of Lipid Research, 50(Suppl), S272-S276.

Maceyka, M., Sankala, H., Hait, N. C., Le Stunff, H., Liu, H., Toman, R., Collier, C., et al. (2005). SphK1 and SphK2, sphingosine kinase isoenzymes with opposing functions in sphingolipid metabolism. The Journal of Biological Chemistry, 280, 37118-37129.

Maggio, B., Fanani, M. L., Rosetti, C. M., \& Wilke, N. (2006). Biophysics of sphingolipids II. Glycosphingolipids: an assortment of multiple structural information transducers at the membrane surface. Biochimica et Biophysica Acta, 1758, 1922-1944.

Mandon, E. C., Ehses, I., Rother, J., van Echten, G., \& Sandhoff, K. (1992). Subcellular localization and membrane topology of serine palmitoyltransferase, 3-dehydrosphinganine reductase, and sphinganine $\mathrm{N}$-acyltransferase in mouse liver. The Journal of Biological Chemistry, 267, 11144-11148.

Manicke, N. E., Wiseman, J. M., Ifa, D. R., \& Cooks, R. G. (2008). Desorption Electrospray Ionization (DESI) Mass Spectrometry and Tandem Mass Spectrometry (MS/MS) of Phospholipids and 
Sphingolipids: Ionization, Adduct Formation, and Fragmentation. Journal of the American Society for Mass Spectrometry, 19, 531-543.

McFarland, M. A., Marshall, A. G., Hendrickson, C. L., Nilsson, C. L., Fredman, P., \& Mansson, J. E. (2005). Structural characterization of the GM1 ganglioside by infrared multiphoton dissociation, electron capture dissociation, and electron detachment dissociation electrospray ionization FT-ICR MS/MS. Journal of the American Society for Mass Spectrometry, 16, 752-762.

McLean, J. A., Ridenour, W. B., \& Caprioli, R. M. (2007). Profiling and imaging of tissues by imaging ion mobility-mass spectrometry. Journal of Mass Spectrometry and Ion Physics, 42, 1099-1105.

Merrill, A. H., Jr. (2002). De novo sphingolipid biosynthesis: a necessary, but dangerous, pathway. The Journal of Biological Chemistry, 277, 25843-25846.

Merrill, A. H., Jr. (2008). Sphingolipids. In D. E. Vance \& J. E. Vance (Eds.), Biochemistry of Lipids, Lipoproteins and Membranes (4th edn, pp. 363-397). Elsevier.

Merrill, A. H., Jr., Stokes, T. H., Momin, A., Park, H., Portz, B. J., Kelly, S., et al. (2009). Sphingolipidomics: a valuable tool for understanding the roles of sphingolipids in biology and disease. Journal of Lipid Research, 50(Suppl), S97-S102.

Merrill, A. H., Jr., Sullards, M. C., Allegood, J. C., Kelly, S., \& Wang, E. (2005). Sphingolipidomics: high-throughput, structure-specific, and quantitative analysis of sphingolipids by liquid chromatography tandem mass spectrometry. Methods, 36, 207.

Merrill, A. H., Jr., Wang, M. D., Park, M., \& Sullards, M. C. (2007). (Glyco)sphingolipidology: an amazing challenge and opportunity for systems biology. Trends in Biochemical Sciences, 32, $457-468$

Michel, C., van Echten-Deckert, G., Rother, J., Sandhoff, K., Wang, E., \& Merrill, A. H., Jr. (1997). Characterization of ceramide synthesis. A dihydroceramide desaturase introduces the 4, 5trans-double bond of sphingosine at the level of dihydroceramide. The Journal of Biological Chemistry, 272, 22432-22437.

Milstien, S., Gude, D., \& Spiegel, S. (2007). Sphingosine 1-phosphate in neural signalling and function. Acta Paediatrica. Supplement, 96, 40-43.

Mizutani, Y., Kihara, A., \& Igarashi, Y. (2005). Mammalian Lass6 and its related family members regulate synthesis of specific ceramides. Biochemical Journal, 390, 263-271.

Murphy, R. C., Hankin, J. A., \& Barkley, R. M. (2009). Imaging of lipid species by MALDI mass spectrometry. Journal of Lipid Research, 50, S317-S322.

Nakamura, K., Suzuki, Y., Goto-Inoue, N., Yoshida-Noro, C., \& Suzuki, A. (2006). Structural characterization of neutral glycosphingolipids by thin-layer chromatography coupled to matrixassisted laser desorption/ionization quadrupole ion trap time-offlight MS/MS. Analytical Chemistry, 78, 5736-5743.

Ngamukote, S., Yanagisawa, M., Ariga, T., Ando, S., \& Yu, R. K. (2007). Developmental changes of glycosphingolipids and expression of glycogenes in mouse brains. Journal of Neurochemistry, 103, 2327-2341.

Omae, F., Miyazaki, M., Enomoto, A., Suzuki, M., Suzuki, Y., \& Suzuki, A. (2004). DES2 protein is responsible for phytoceramide biosynthesis in the mouse small intestine. Biochemical Journal, 379, 687-695.

Pacetti, D., Boselli, E., Hulan, H. W., \& Frega, N. G. (2005). High performance liquid chromatography-tandem mass spectrometry of phospholipid molecular species in eggs from hens fed diets enriched in seal blubber oil. Journal of Chromatography. A, 1097, 66-73.

Pan, B., Fromholt, S. E., Hess, E. J., Crawford, T. O., Griffin, J. W., Sheikh, K. A., et al. (2005). Myelin-associated glycoprotein and complementary axonal ligands, gangliosides, mediate axon stability in the CNS and PNS: Neuropathology and behavioral deficits in single- and double-null mice. Experimental Neurology, 195, 208-217.

Pettus, B. J., Bielawska, A., Kroesen, B. J., Moeller, P. D., Szulc, Z. M., Hannun, Y. A., et al. (2003). Observation of different ceramide species from crude cellular extracts by normal-phase high-performance liquid chromatography coupled to atmospheric pressure chemical ionization mass spectrometry. Rapid Communications in Mass Spectrometry, 17, 1203-1211.

Pettus, B. J., Kroesen, B. J., Szulc, Z. M., Bielawska, A., Bielawski, J., Hannun, Y. A., et al. (2004). Quantitative measurement of different ceramide species from crude cellular extracts by normal-phase high-performance liquid chromatography coupled to atmospheric pressure ionization mass spectrometry. Rapid Communications in Mass Spectrometry, 18, 577-583.

Pewzner-Jung, Y. B.-D. S., \& Futerman, A. H. (2006). When do Lasses (longevity assurance genes) become CerS (ceramide synthases)?: Insights into the regulation of ceramide synthesis. The Journal of Biological Chemistry. 2006 Sep 1, 281(35): 25001-5., 281:5.

Pol, J., Vidova, V., Kruppa, G., et al. (2009). Automated ambient desorption-ionization platform for surface imaging integrated with a commercial Fourier transform ion cyclotron resonance mass spectrometer. Analytical Chemistry, 81, 8479-8487.

Pruett, S. T., Bushnev, A., Hagedorn, K., Adiga, M., Haynes, C. A., Sullards, M. C., et al. (2008). Biodiversity of sphingoid bases ("sphingosines") and related amino alcohols. Journal of Lipid Research, 49, 1621-1639.

Quarles, R. H. (2007). Myelin-associated glycoprotein (MAG): Past, present and beyond. Journal of Neurochemistry, 100, 14311448.

Riebeling, C., Allegood, J. C., Wang, E., Merrill, A. H., Jr., \& Futerman, A. H. (2003). Two mammalian longevity assurance gene (LAG1) family members, trh1 and trh4, regulate dihydroceramide synthesis using different fatty acyl-CoA donors. The Journal of Biological Chemistry, 278, 43452-43459.

Roy, S., Touboul, D., Brunelle, A., Germain, D. P., Prognon, P., Laprevote, O., et al. (2006). Imaging mass spectrometry: a new tool for the analysis of skin biopsy. Application in Fabry's disease. Annales Pharmaceutiques Françaises, 64, 328-334.

Sandhoff, R., Geyer, R., Jennemann, R., et al. (2005). Novel class of glycosphingolipids involved in male fertility. The Journal of Biological Chemistry, 280, 27310-27318.

Schiopu, C., Flangea, C., Capitan, F., Serb, A., Vukelic, Z., KalanjBognar, S., et al. (2009). Determination of ganglioside composition and structure in human brain hemangioma by chip-based nanoelectrospray ionization tandem mass spectrometry. Analytical and Bioanalytical Chemistry, 395, 2465-2477.

Schulze, H., Kolter, T., \& Sandhoff, K. (2009). Principles of lysosomal membrane degradation: Cellular topology and biochemistry of lysosomal lipid degradation. Biochimica et Biophysica Acta, 1793, 674-683.

Schwarz, A., \& Futerman, A. H. (1997). Distinct roles for ceramide and glucosylceramide at different stages of neuronal growth. Journal of Neuroscience, 17, 2929-2938.

Schwarz, A., Rapaport, E., Hirschberg, K., \& Futerman, A. H. (1995). A regulatory role for sphingolipids in neuronal growth. Inhibition of sphingolipid synthesis and degradation have opposite effects on axonal branching. The Journal of Biological Chemistry, 270, 10990-10998.

Shaner, R. L., Allegood, J. C., Park, H., Wang, E., Kelly, S., Haynes, C. A., et al. (2009). Quantitative analysis of sphingolipids for lipidomics using triple quadrupole and quadrupole linear ion trap mass spectrometers. Journal of Lipid Research, 50, 1692-1707. 
Shayman, J. A., \& Abe, A. (2000). Glucosylceramide synthase: Assay and properties. Methods in Enzymology, 311, 42-49.

Siskind, L. J., Kolesnick, R. N., \& Colombini, M. (2006). Ceramide forms channels in mitochondrial outer membranes at physiologically relevant concentrations. Mitochondrion, 6, 118-125.

Sjovall, P., Lausmaa, J., \& Johansson, B. (2004). Mass spectrometric imaging of lipids in brain tissue. Analytical Chemistry, 76, $4271-4278$.

Sommer, U., Herscovitz, H., Welty, F. K., \& Costello, C. E. (2006). LC-MS-based method for the qualitative and quantitative analysis of complex lipid mixtures. Journal of Lipid Research, 47, 804-814.

Sprong, H., Degroote, S., Nilsson, T., Kawakita, M., Ishida, N., van der Sluijs, P., et al. (2003). Association of the Golgi UDPgalactose transporter with UDP-galactose:ceramide galactosyltransferase allows UDP-galactose import in the endoplasmic reticulum. Molecular Biology of the Cell, 14, 3482-3493.

Sprong, H., Kruithof, B., Leijendekker, R., Slot, J. W., van Meer, G., \& van der Sluijs, P. (1998). UDP-galactose:ceramide galactosyltransferase is a class I integral membrane protein of the endoplasmic reticulum. The Journal of Biological Chemistry, 273, 25880-25888.

Stahlman, M., Ejsing, C. S., Tarasov, K., Perman, J., Boren, J., \& Ekroos, K. (2009). High-throughput shotgun lipidomics by quadrupole time-of-flight mass spectrometry. Journal of Chromatography. B, Analytical Technologies in the Biomedical and Life Sciences, 877, 2664-2672.

Stuebiger, G., \& Belgacem, O. (2007). Analysis of Lipids Using 2, 4, 6-Trihydroxyacetophenone as a Matrix for MALDI Mass Spectrometry. Analytical Chemistry, 79, 3206-3213.

Sugiura, Y., Shimma, S., Konishi, Y., Yamada Maki, K., \& Setou, M. (2008). Imaging mass spectrometry technology and application on ganglioside study; visualization of age-dependent accumulation of C20-ganglioside molecular species in the mouse hippocampus. PLoS One, 3, e3232.

Sullards, M. C. (2000). Analysis of sphingomyelin, glucosylceramide, ceramide, sphingosine, and sphingosine 1-phosphate by tandem mass spectrometry. Methods in Enzymology, 312, 32-45.

Sullards, M. C., Allegood, J. C., Kelly, S., Wang, E., Haynes, C. A., Park, H., et al. (2007). Structure-specific, quantitative methods for analysis of sphingolipids by liquid chromatography-tandem mass spectrometry: "inside-out" sphingolipidomics. Methods in Enzymology, 432, 83-115.

Sullards, M. C., \& Merrill, A. H., Jr. (2001). Analysis of sphingosine 1-phosphate, ceramides, and other bioactive sphingolipids by high-performance liquid chromatography-tandem mass spectrometry. Sci STKE, 2001, PL1.

Susuki, K., Baba, H., Tohyama, K., et al. (2007). Gangliosides contribute to stability of paranodal junctions and ion channel clusters in myelinated nerve fibers. Glia, 55, 746-757.

Suzuki, Y., Suzuki, M., Ito, E., Goto-Inoue, N., Miseki, K., Iida, J., et al. (2006). Convenient structural analysis of glycosphingolipids using MALDI-QIT-TOF mass spectrometry with increased laser power and cooling gas flow. Journal of Biochemistry, 139, 771-777.

Svennerholm, L., Bostrom, K., Fredman, P., Mansson, J. E., Rosengren, B., \& Rynmark, B. M. (1989). Human brain gangliosides: developmental changes from early fetal stage to advanced age. Biochimica et Biophysica Acta, 1005, 109-117.

Tani, M., Igarashi, Y., \& Ito, M. (2005). Involvement of neutral ceramidase in ceramide metabolism at the plasma membrane and in extracellular milieu. The Journal of Biological Chemistry, 280, 36592-36600.

Tettamanti, G., Bassi, R., Viani, P., \& Riboni, L. (2003). Salvage pathways in glycosphingolipid metabolism. Biochimie, 85, 423-437.
Trimpin, S., Tan, B., Bohrer, B. C., O’Dell, D. K., Merenbloom, S. I., Pazos, M. X., et al. (2009). Profiling of phospholipids and related lipid structures using multidimensional ion mobility spectrometry-mass spectrometry. International Journal of Mass Spectrometry and Ion Physics, 287, 58-69.

Vacaru, A. M., Tafesse, F. G., Ternes, P., Kondylis, V., Hermansson, M., Brouwers, J. F., et al. (2009). Sphingomyelin synthaserelated protein SMSr controls ceramide homeostasis in the ER. Journal of Cell Biology, 185, 1013-1027.

van Echten-Deckert, G., \& Herget, T. (2006). Sphingolipid metabolism in neural cells. Biochimica et Biophysica Acta, 1758, 1978-1994.

Van Overloop, H., Gijsbers, S., \& Van Veldhoven, P. P. (2006). Further characterization of mammalian ceramide kinase: substrate delivery and (stereo)specificity, tissue distribution, and subcellular localization studies. Journal of Lipid Research, 47, 268-283.

Verbeck, G. F., Ruotolo, B. T., Sawyer, H. A., Gillig, K. J., \& Russell, D. H. (2002). A fundamental introduction to ion mobility mass spectrometry applied to the analysis of biomolecules. Journal of Biomolecular Technology, 13, 56-61.

Vukelic, Z., Kalanj-Bognar, S., Froesch, M., Bindila, L., Radic, B., Allen, M., et al. (2007). Human gliosarcoma-associated ganglioside composition is complex and distinctive as evidenced by high-performance mass spectrometric determination and structural characterization. Glycobiology, 17, 504-515.

Williams, R. D., Wang, E., \& Merrill, A. H., Jr. (1984). Enzymology of long-chain base synthesis by liver: characterization of serine palmitoyltransferase in rat liver microsomes. Archives of Biochemistry and Biophysics, 228, 282-291.

Wiseman, J. M., Ifa, D. R., Song, Q., \& Cooks, R. G. (2006). Tissue imaging at atmospheric pressure using desorption electrospray ionization (DESI) mass spectrometry. Angewandte Chemie (International ed. in English), 45, 7188-7192.

Woods, A. S., \& Jackson, S. N. (2006). Brain tissue lipidomics: direct probing using matrix-assisted laser desorption/ionization mass spectrometry. The AAPS Journal, 8, E391-E395.

Yoo, H. H., Son, J., \& Kim, D.-H. (2006). Liquid chromatographytandem mass spectrometric determination of ceramides and related lipid species in cellular extracts. Journal of Chromatography. B, Analytical Technologies in the Biomedical and Life Sciences, 843, 327-333.

Yoon, S. J., Nakayama, K., Hikita, T., Handa, K., \& Hakomori, S. I. (2006). Epidermal growth factor receptor tyrosine kinase is modulated by GM3 interaction with N-linked GlcNAc termini of the receptor. Proceedings of the National Academy of Sciences of the United States of America, 103, 18987-18991.

Yu, R. K., Bieberich, E., Xia, T., \& Zeng, G. (2004). Regulation of ganglioside biosynthesis in the nervous system. Journal of Lipid Research, 45, 783-793.

Yu, R. K., Nakatani, Y., \& Yanagisawa, M. (2009). The role of glycosphingolipid metabolism in the developing brain. Journal of Lipid Research, 50(Suppl), S440-S445.

Zarei, M., Bindila, L., Souady, J., Dreisewerd, K., Berkenkamp, S., Muething, J., et al. (2008). A sialylation study of mouse brain gangliosides by MALDI a-TOF and o-TOF mass spectrometry. Journal of Mass Spectrometry and Ion Physics, 43, 716-725.

Zeng, G., \& Yu, R. K. (2008). Cloning and transcriptional regulation of genes responsible for synthesis of gangliosides. Current Drug Targets, 9, 317-324.

Zheng, W., Kollmeyer, J., Symolon, H., et al. (2006). Ceramides and other bioactive sphingolipid backbones in health and disease: lipidomic analysis, metabolism and roles in membrane structure, dynamics, signaling and autophagy. Biochimica et Biophysica Acta, 1758, 1864-1884. 
Zitomer, N. C., Mitchell, T., Voss, K. A., et al. (2009). Ceramide synthase inhibition by fumonisin B1 causes accumulation of 1-deoxysphinganine: a novel category of bioactive 1-deoxysphingoid bases and 1-deoxydihydroceramides biosynthesized by mammalian cell lines and animals. The Journal of Biological Chemistry, 284, 4786-4795. 